\title{
Article
}

\section{In real life: evaluating primary care based undergraduate dental education in Northwest England}

Kuroski, Jennifer, Rouse, Karen Ann, Cook, Neil, Magee, Angela Patricia and Welbury, Richard

Available at http://clok.uclan.ac.uk/25482/

Kuroski, Jennifer ORCID: 0000-0002-4406-5127, Rouse, Karen Ann ORCID: 0000-0002-3379-5722, Cook, Neil ORCID: 0000-0001-9738-9582, Magee, Angela Patricia and Welbury, Richard ORCID: 0000-0002-9322-2440 (2019) In real life: evaluating primary care based undergraduate dental education in Northwest England. British Dental Journal, 226 . pp. 605-610. ISSN 0007-0610

It is advisable to refer to the publisher's version if you intend to cite from the work. http://dx.doi.org/10.1038/s41415-019-0204-z

For more information about UCLan's research in this area go to

http://www.uclan.ac.uk/researchgroups/ and search for <name of research Group>.

For information about Research generally at UCLan please go to http://www.uclan.ac.uk/research/

All outputs in CLoK are protected by Intellectual Property Rights law, including Copyright law. Copyright, IPR and Moral Rights for the works on this site are retained by the individual authors and/or other copyright owners. Terms and conditions for use of this material are defined in the policies page.

\section{CLoK}

Central Lancashire online Knowledge www.clok.uclan.ac.uk

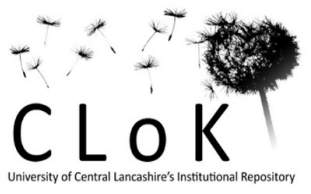


Title:

In real life: evaluating primary care based undergraduate dental education in Northwest England

\title{
Running title:
}

Dental students' views about treating patients in primary care in under-served areas

\begin{abstract}
:
Aim: To explore how working at Dental Education Centres (DECs), away from the university campus, has influenced the attitudes of dental students towards providing dental care in a primary setting, and whether students feel that this model of dental education meets their perceived training needs.
\end{abstract}

Design: Exploratory, qualitative interview study.

Methods: Semi-structured interviews with five $4^{\text {th }}$ BDS students analysed using thematic analysis.

Results: The main theme identified was 'real life dentistry' as students described how their clinical experiences and the teaching at DECs would prepare them for life as a general dental practitioner. Students felt they had a positive impact on their patients, and although some felt they could not comment on the impact to the community, others thought that this was likely to be positive.

Discussion: Students believed they experienced 'real life dentistry' which would prepare them well for their foundation year and future practice. They also believed they had a positive impact on their patients. 


\section{Introduction}

The benefits of dental education in outreach settings worldwide are well documented, including: quantity and range of treatments carried out, a higher volume of patients (compared to dental hospitals), experience of team working, encouraging students to work in underserved and rural areas, and a reduction of dental need in these areas (1-7).

Traditional UK dental schools value "outreach placements" in primary care settings for students on Bachelor of Dental Surgery (BDS) courses, with the duration varying between schools. Benefits for students include: opportunities for team working with a dental nurse, improved time management, increased confidence, higher volumes of patients and more varied procedures (8-14).

\section{Local context}

In 2008 the North-West of England had a shortage of NHS primary dental care (15) and high dental need, with levels of decayed or missing teeth at least $50 \%$ higher than the average for England (16). The University of Central Lancashire (UCLan) School of Dentistry opened in September 2007. In 2008, in partnership with four Primary Care Trusts, four community-based Dental Education Centres (DECs) were opened in Blackpool, Morecambe, Accrington and Carlisle. In this 'hub and spoke' model, the dental school in Preston acts as a 'hub' and the DECs as 'spokes'. As students treating patients in under-served communities are more likely to treat such populations after graduating $(5,17)$, and are reported to have more positive professional attitudes and behaviours regarding those patients (18), one hope of this model was that students, having had experience of treating patients in these areas of high need, would be more likely to opt to remain in these localities after completing their training (15). However, it was acknowledged that this would be dependent to some extent on student rankings in the DF1 recruitment process, which determine to which region a graduate is allocated (19).

The UCLan BDS course is graduate entry, recruiting 29 students annually. Students who have a degree in a relevant subject enter directly into $2^{\text {nd }}$ BDS, which is spent in Preston, learning techniques and theories necessary for effective dental care. From $3^{\text {rd }}$ BDS onwards, groups of eight students gain clinical experience at one of the DECs. Initially students are 'paired', with one carrying out treatment under one-toone tutor supervision, and the other acting as a dental nurse. Once students have transferred to the DECs, they only return to Preston for skills workshops and lecture days. The majority of teaching is face-to-face in the DECs, and by video-conference (VC). Secondary care experience is achieved during placements in local hospitals.

\section{Key differences between UCLan and traditional dental schools}

1) Clinical experience in traditional schools is gained in hospitals near to or within the educational provider, despite more than $95 \%$ of dental graduates working as General Dental Practitioners in primary care settings $(6,20)$. The UCLan DECs operate within primary care, providing students with an authentic experience of working in the settings that they are most likely to encounter after qualification.

2) Hospital linked dental schools usually provide care without charge, whereas DEC patients pay NHS rates for their treatment. UCLan students therefore experience the business side of dentistry. 
3) Whilst at traditional dental schools students treat patients in separate departments, for example restorative or oral surgery, at UCLan a more holistic approach is taken; students at each stage of their training are allocated appropriate patients to allow them to provide all the care needed within the treatment plan.

The only UK dental school with a similar structure to UCLan's is the University of Plymouth Peninsula Dental School (PDS), and we refer to this in the discussion.

\begin{abstract}
Aim
The aim of this study was to examine students' perceptions of the 'hub and spoke' model, the effect working in the DECs has had on their attitudes towards providing dental care in under-served communities, and whether they think the DECs contribute to improvements in oral health locally. This is the first attempt to formally evaluate the course; the evidence to date has been anecdotal.
\end{abstract}

\title{
Methods
}

Approval was gained from the UCLan STEMH ethics committee (project number 579). All $294^{\text {th }}$ BDS students were offered the opportunity to participate in a semistructured interview, either face-to-face or via telephone. $4^{\text {th }}$ BDS were approached because they had worked in the DECs for over a year and had time to form views and opinions on this mode of delivery. $5^{\text {th }}$ BDS were not approached as they were preparing for final examinations. Five $4^{\text {th }}$ BDS students provided written consent to take part.

Interviews were audio recorded. One took place face-to-face and four by telephone. The interview guide was consistent for all interviews and can be found in Table 1 below. Supplementary questions were asked as appropriate to the direction of each discussion.

Table 1: Semi-structured interview schedule

\begin{tabular}{|l|}
\hline Questions \\
\hline Can you tell me about the process you went through to choose a dental school? \\
\hline Were you aware of the hub and spoke structure of the dental school when you applied for \\
to course? \\
\hline Can you describe a typical day at the DECs? \\
\hline What do you like about working in the DECs? \\
\hline Is there anything you would change about the DECs? \\
\hline Do you live near to the DECs? \\
\hline What can you tell me about the community that the DEC is based in? \\
\hline How do you think your education needs are met by the DECs? \\
\hline $\begin{array}{l}\text { Can you tell me about a time you found challenging when providing dental care at the } \\
\text { DECs? }\end{array}$ \\
\hline $\begin{array}{l}\text { Are there any aspects of the care you provide at the DECs where you feel you need more } \\
\text { training or guidance? }\end{array}$ \\
\hline How do you feel that your clinical supervisors support you at the DECs? \\
\hline
\end{tabular}

Interviews were transcribed verbatim by the first author using NVIVO 11 (20). Accounts were anonymised during transcription. Analysis was undertaken by the first author using thematic analysis, following the approach of Braun and Clarke (21). This 
is an inductive, non-linear approach comprising data familiarisation, coding, identifying, defining, checking and modifying themes across codes and writing up. Familiarisation was achieved through transcription and repeated reading of transcripts. Initial, inductive coding of transcripts was then undertaken, resulting in 365 codes. Through an iterative process, these initial codes were organised and combined by topic area into 46 distinct, defined codes, which constituted the initial coding framework. Following testing of the codes, the transcripts were then re-coded and an improved final framework of 22 codes was devised. Themes were then generated by identifying patterns both within and across coded extracts of text. This process is illustrated in Table 2, which shows the initial and final coding schemes, as well as how each of the codes fits into the final set of themes identified.

Table 2: Generation of the final coding framework from the initial codes

\begin{tabular}{|c|c|c|}
\hline Themes & Final Coding Framework & Initial Coding Framework \\
\hline \multirow{24}{*}{ 1. Teaching } & \multirow{2}{*}{ Relationship with other students } & Nursing for other students \\
\hline & & Support - students \\
\hline & Relationship with tutors & Support from tutors \\
\hline & Student decisions before training & Decisions - Applying to Dental School \\
\hline & \multirow{4}{*}{ Student perceptions: benefits } & Benefits of DEC Location \\
\hline & & Benefits of Teaching \\
\hline & & Benefits- Time (1) ${ }^{1}$ \\
\hline & & Decisions - Reasons for choosing UCLan $(1)^{1}$ \\
\hline & Student perceptions: comparisons between DECs & Comparisons - Between DECs \\
\hline & Student perceptions: comparisons between GDPs & Comparison - GDPs \\
\hline & \multirow{2}{*}{$\begin{array}{l}\text { Student perceptions: comparisons with other dental } \\
\text { schools }\end{array}$} & Comparisons - Oher dental schools \\
\hline & & Other dental schools \\
\hline & \multirow{2}{*}{ Student perceptions: perceived issues } & Issues-Challenges at DEC \\
\hline & & Issues-Challenges with Teaching \\
\hline & \multirow{9}{*}{ Student perceptions: teaching } & Academic Teaching \\
\hline & & Clinical Teaching \\
\hline & & Confidence \\
\hline & & Dental procedures \\
\hline & & Home \\
\hline & & Knowledge of the DECs \\
\hline & & Perceptions of Dental Nurses \\
\hline & & Perceptions of Tutors \\
\hline & & Placements \\
\hline & Teaching & Treatment at DEC \\
\hline \multirow{2}{*}{ 2. Patients } & \multirow{2}{*}{ Student perceptions: patients } & Anxious Patients \\
\hline & & Perceptions of patients \\
\hline \multirow{3}{*}{ 3. DEC location } & Student decisions after training & Decisions - Future \\
\hline & \multirow{2}{*}{ Student perceptions: DEC location } & DEC Location \\
\hline & & High Dental Need \\
\hline \multirow{7}{*}{ 4a. Impact: patients } & \multirow{2}{*}{ Relationship with patients } & Patient Expectations \\
\hline & & Rapport with patients \\
\hline & \multirow{2}{*}{ Student decisions during training } & Decisions - Patients \\
\hline & & Treatment Planning \\
\hline & Student perceptions: benefits & 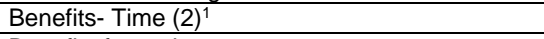 \\
\hline & \multirow{2}{*}{ Student perceptions: impact on patients } & Benefits for patients \\
\hline & & Drawbacks for the patient \\
\hline 4b. Impact: community & Student perceptions: impact on the community & Benefits for the community \\
\hline \multirow{7}{*}{ 4c. Impact: students } & Student perceptions: benefits & Decisions - Reasons for choosing UCLan (2) ${ }^{1}$ \\
\hline & Student perceptions: impact on students & Benefits - Students \\
\hline & \multirow{5}{*}{ Student perceptions: perceived issues } & Issues-Challenges - DEC Location \\
\hline & & Need for information \\
\hline & & Patient Attendance \\
\hline & & Practice \\
\hline & & Students wants or suggestions \\
\hline \multirow[b]{2}{*}{ Removed } & \multirow[b]{2}{*}{ Removed } & Personal (discarded on anonymisation of quotes) \\
\hline & & $\begin{array}{l}\text { Comparison ETPs (enhanced training practices) } \\
\text { (removed, not relevant) }\end{array}$ \\
\hline
\end{tabular}




\section{Reflexivity}

The research assistant who conducted the interviews was not a dentist, had no involvement in students' day to day teaching and had no prior knowledge that could have influenced interview interpretation. Expert support for interpretation was provided by other members of the study team.

\section{Results}

The final themes - teaching, patients, DEC location and impact - were linked together by the overarching theme of "real life dentistry" as illustrated in in Figure 1 below, with students describing how their learning experiences are: "[...]A lot more organic and realistic [which] better prepares you for the real world..." (DEC004). These themes are now described and illustrated using verbatim quotes from participants.

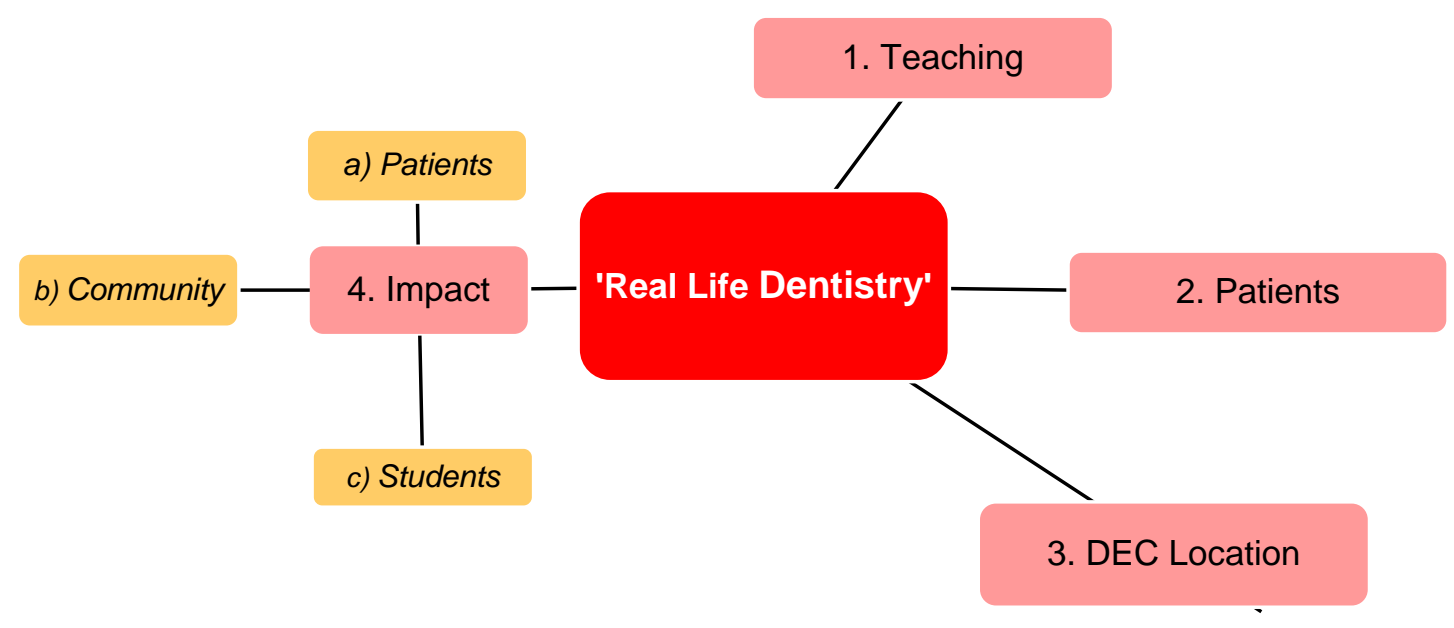

Figure 1: Thematic Map

\section{Perceptions of Teaching}

Students appreciated the course being 'graduate entry', a year shorter than other courses, and the 'NHS' bursary. Compared to a traditional approach, students considered the DECs more 'holistic'., "[...] You're treating everything.. for the patient and you treat them as you would in a dental practice." (DEC005). Students believed that the DECs are: "[...] like a general practice rather than a specific type of dental area." (DEC0003) and give students experience in "[...] basically anything that an NHS dentist would be expected to do... except the stuff you require training for ..." (DEC004). Additionally, they valued having 'repeat patients' and 'building up your skills with the same patients'.

Most students noted that the DECs provided more variety "[...] Here it's all done on the same department and you're all doing different things at once." (DEC003). Students also appreciated the 'variety' of tutors they saw on clinic and how this allowed them to gain experience with different areas in dentistry. However, some 
students found it difficult to make comparisons between the DECs, "[...] basically we have no idea [...] what their DEC looks like, how it works for them..." (DEC005), and seemed unaware of the measures in place to calibrate teaching across the DECs.

Students start their clinical training in the phantom head room at Preston, returning periodically to complete courses on 'root canals', 'endodontics', 'crowns', 'indirect restorations', 'bridges' and 'immediate life support'. Patients' treatment occurs after completion of the relevant course. Students noted "[...] we can work separately with nurses if we've got clashes of patients" (DEC004) Some students felt that "[...] UCLan start their clinical work early compared to some people, I know some people don't pick up a hand piece until their third year into their degree." (DEC004).

When starting at the DECs, students described 'getting good at the basics' and as they progressed through the course 'building on knowledge you've already got'. They were also aware that as their skills developed, they became more able to complete the treatment plan, "[...] as you prime your patients and get them ready to actually have the treatment, [...] you're also building up your skills to be able to provide it. So it's quite a logical, chronological order to go through." (DEC001). They also valued being taught: "what to treat and what not to treat and to recognise when to send a referral letter on to the right person" (DEC001) if a patient was beyond their "scope of practice'. One student described receiving 'smaller group teaching' or 'tutorials' on clinic, "[...] so if we get a cancellation and we can't get a triage patient in, or if it's quiet on EDS [Emergency Dental Service] that day.. we ask the tutor to give us mini tutorials." (DEC002). One student felt that placements should be on a non-clinic day "I would like to go on secondary care placements on a study day or on a day when we don't have clinic normally so that I'm not missing out on any clinic time..." (DEC001).

Students felt well supported by their tutors, describing them as, "really good, really open and approachable" (DEC004). Students appreciated the way tutors gave them feedback on their work by providing 'constructive criticism'. They felt that their tutors knew them well enough to provide appropriate support, "I had my first crown the other day and my tutor knew I was a bit nervous so they came in more than they would for anything else. [...]. So it's all dependent on how much help you need [...] But they don't tend to take over unless you ask them to. It's supportive in the right way I think." (DEC002).

Students described supporting each other, particularly in their clinical pairs, "We tend to ask each other's opinions if we're struggling. [...] we're both learning we're both at the same stage and we don't mind the input." (DEC002). They also sought advice during their breaks, "[...] we talk through difficult cases we're having 'cause people have different ways of looking at things, you might have missed something that someone else remembers from a lecture..." (DEC004)

Students noted improvements to their communication skills, one student described how they were "[...] not the most outgoing or talkative person in the world so getting practice and building rapport with patients is absolutely crucial" and "if I hadn't had as much experience" they would have "found it [general practice] much more difficult." (DEC004). Students appreciated seeing the same patients "[...] we get to know them and explain changes during the treatment planning process..." (DEC002). One student also enjoyed the opportunity to meet local dentists, "[...] you do network, you 
meet dentists[...] so you get to know them and I guess that will help you to decide if you would want to stay in the area and work with one of those one day." (DEC003)

\section{Perceptions about Patients}

Students felt DEC patient populations may differ including: 'younger', 'middle aged', 'older', 'retired' or 'working shifts'. All students described patients as having a 'high dental need' with some experiencing a 'period of [dental] neglect'. Students described patients with 'substance dependency', as well as 'anxious' or 'dentally phobic' patients who may only seek treatment when 'in pain' due to a 'bad experience in the past'. Many anxious patients were referred from the 'Emergency Dental Service' and some would 'fail to attend' appointments. Students described how 'inhalation sedation' was available at the DEC and this helped anxious patients during treatment.

\section{Perceptions about DEC Location}

Students described DECs as being based in areas of 'high dental need' or 'dental deprivation' and realised this was their purpose, "[...]the purpose of putting a DEC there was... that goes for all four DECs, they put them in areas of high dental need and you can see it with the patients that come in" (DEC002). Views of the DEC locations, were both positive and negative, ranging from 'slower pace of life' and having a 'local community feel to it' to 'socioeconomically deprived' or 'not a very nice area'. Commitment to the local community was varied, some students described how they spent 'limited' time in the community around the DEC and 'don't really know the area'. One student felt their knowledge of the area was a 'good icebreaker'.

Most of the students interviewed discussed returning home or close to friends and family after they qualified, "Ideally I want to move back home..." (DEC002). However some students would consider staying in the area near to their DEC "[...] I'm not averse to staying in the area, perhaps I will in VT year after I graduate." [DEC001]. This may be due to the students being in $4^{\text {th }}$ BDS, whereas previous studies were based on the location of students during or after their foundation year. Student perceptions of their DEC's location were important; those who saw the area positively or had family or friends in the area thought they would be more likely to return.

\section{4a. Impact on Patients}

Students described how patients receive 'holistic' and 'continuity of care' and believed the DECs were accessible for patients, "[...] it will definitely encourage people to go [to the DECs] because it is local and it's quite easily accessible for them... and it's NHS" (DEC003). Students believed NHS dental treatment is "hard to find". They also felt patients referred from the EDS were treated faster, "[...] say the dentist doesn't have a free availability until $5 \mathrm{pm}$ then [...] you can see the dentist later on in the day or you can see a student earlier in the day..." (DEC002).

Students believed 'longer' appointment times were appreciated by the patients, especially those that were 'anxious', "[...] this particular patient said they enjoyed the longer appointment times because it gave them the chance to relax a little bit more and [... ]build more of a rapport with myself and the other team members [...] this particular patient has come a long way from [...] close to being dental phobic to not dreading coming in..." (DEC003) or patients with disabilities, "[...] we see a lot of patients who perhaps they're in a wheelchair, they've got fairly complex health needs $[. .$.$] and it physically takes them ten minutes to get in the dental chair [...] They might$ 
not be particularly suitable for a busy general practice whereas we can see them and we don't have that time pressure." (DEC001)

Students considered patients' circumstances such as 'drug interactions', amount of 'time off work' and 'cost', before deciding on the most appropriate treatment plan. Students wanted the best for their patients when considering treatment options "[...]it's just choosing the best one for the patient, what the patient wants and just assessing whether that's ethical given the state of their oral health." (DEC005).

\section{4b. Impact on the community}

Some students felt that the impact of the DEC on the community was limited to "making sure that the patients who need a lot of treatment actually get it." (DEC001), others saw a more positive impact: "[...] I think it's helped because of the big waiting lists before and I don't think the waiting list exists anymore..." (DEC005)

\section{4c. Impact on students}

Students felt that in a larger dental school they might get 'lost in the system' and preferred a 'smaller more personal school' with a good 'staff to student ratio'. They also felt part of the team, "I like the fact that we're treated more like adults [...] we've got our own common room with access to a kitchen so it does feel like this place is ours as well as the staff ..." (DEC005)

Students described lectures as either full-day sessions at Preston or via 'videoconferencing' with lectures broadcast from Preston to all of the DECs. There were issues with both; lecture days were described as 'fast paced' whilst VC lectures could be 'difficult' or 'boring' as students felt 'disconnected' or 'detached'. However, they did appreciate that both methods reduced travel between the DECs and Preston, which some felt could 'grind you down'. "[...] It's not quite the same as having a lecture in the same room. It's like $90 \%$ of the way there and I suppose [...] it's much better than having everyone travel to Preston...." (DEC004). Students appreciated that lectures were recorded "Lecture recordings can all be saved and they're uploaded to Blackboard so you can watch them back if you feel like you've missed anything." (DEC004).

Students discussed 'time management' and balancing their clinical and academic workloads, in particular the amount of patients they see "The challenge is getting the balance right between having enough patients on the books to keep yourself busy and learning but not having too many that other patients' are disadvantaged by a long wait." (DEC001)

\section{Discussion}

Students believed the DECs provided experience of 'real life dentistry' reflecting general practice. They valued developing skills with the same patients, improving their communication skills and working with 'high dental need' or 'anxious' patients. They liked providing holistic, continuous, NHS care. Students considered various factors whilst building treatment plans. They felt the DECs were accessible for patients especially those who were anxious or had complex health needs. They were uncertain of the impact of the DECs upon the community but some felt it was positive. Students felt supported and part of the team due to UCLan being a 'smaller more personal school'. 
The overarching theme of 'real life dentistry' fits with findings from other studies $(3,7$, 22), where students felt their experiences at outreach centres closely reflected real life dental experience. Students in previous studies also valued factors such as: treating patients holistically, gaining knowledge of treatment planning, increased awareness of the variety of patient needs, wide range of clinical experience, working with the wider dental team and increased confidence and speed $(1,3,6-8,14)$.

Our findings are echoed in a recent study of three dental schools, one of which was graduate entry, looking at preparedness of final year students for independent general dental practice, which found that the most important factor was clinical exposure to patients. Students working in outreach settings valued being able to plan treatments with educators from general dental practice, and they felt that this was beneficial in their development. (23).

The findings also link to a study of students from Kings Dental Institute attending outreach placement at Portsmouth Dental Academy, which concluded that students "valued the immersion in clinical dentistry and the bridging from dental school to their dental foundation training." (24), and a separate study at Portsmouth which found that staff contributed to the students feeling valued (23). Similarly, students' outreach training at PDS has been described as "embedded in the community" (25), where learning is delivered in context, with students treating patients from very early in the course (26).

As stated in the introduction, many traditional dental schools in the UK value outreach placements in primary care settings. However, the duration of these varies widely, encompassing both block placements and regular rotations (8-14). In contrast, at UCLan, once students have transferred to the DECs in $3^{\text {rd }}$ BDS, they return only occasionally to Preston to participate in skills workshops and attend monthly lecture days. This is a more extensive experience of outreach teaching, which, combined with the smaller cohort size, has resulted in students feeling like team members than just one of a number of students (cf. section 4c: impact on students).

Students had a wide range of views about the location in which their DEC was based. Those who had more positive views about the DEC's location reported that they would be more likely to return and practice there in the future. However, contrary to historical research $(18,27-29)$ most students in this study would prefer to return home or close to friends and family.

We acknowledge that the sample recruited was small. However, we believe that our data has sufficient information power (30) to be able to adequately inform our research aims. The aim of the study was narrow (pertaining to views of a single mode of dental education delivery), with a very specific target population, were partly informed by anecdotal feedback, and interviews consisted of what we determined to be quality dialogue, totalling 227 minutes and featuring open and honest discussions which were facilitated by the interviewer's impartial stance. As with any qualitative research, more interviews may have generated further insights, but we note that the content of our interviews was relatively homogenous and in line with anecdotal feedback previously received. We are currently undertaking research which will strengthen these findings by examining clinical supervisors' and dental nurses' 
perspectives and a future study exploring patient views is planned. These findings could also be used to develop a questionnaire that allows us to investigate the perceptions of a larger sample, including current cohorts and past students. The questionnaire would provide direction for improving the course, which in turn could improve patient care.

\section{Conclusion}

The study examines a novel approach to dental education. Basing dental training within primary care has been commented on favourably in the recent report Advancing Dental Care, which concluded that a concern about graduates being "unable to work safely and independently" could be allayed by means such as "increasing the number of outreach opportunities for students and facilitating more primary care work experience" (31). Although the 'hub and spoke' model is unique to UCLan, the findings have supported those from other studies and may be applicable to other outreach models. The UCLan experience of providing "real life dentistry" will be of interest to other dental schools offering outreach teaching or considering adopting a similar model. 


\section{$\underline{\text { References }}$}

1. Eaton KA, De Vries J, Widström E, Gait TC, Bedi R, Meyers I, et al. 'Schools without walls?'Developments and challenges in dental outreach teaching-report of a recent symposium. European Journal of Dental Education. 2006;10(4):186-91.

2. Steele L, Pacza T, Tennant M. Rural and remote oral health, problems and models for improvement: a Western Australian perspective. Australian Journal of Rural Health. 2000;8(1):22-8. 3. Eriksen HM, Bergdahl M, Byrkjeflot LI, Crossner CG, Widström E, Tillberg A. Evaluation of a dental outreach teaching programme. European Journal of Dental Education. 2011;15(1):3-7. 4. Hatcher AM, Onah M, Kornik S, Peacocke J, Reid S. Placement, support, and retention of health professionals: national, cross-sectional findings from medical and dental community service officers in South Africa. Human Resources for Health. 2014;12(1):1.

5. McQuistan MR, Kuthy RA, Qian F, Riniker - Pins KJ, Heller KE. Dentists' treatment of underserved populations following participation in community - based clinical rotations as dental students. Journal of Public Health Dentistry. 2010;70(4):276-84.

6. Elkind A. Outreach teaching: is this the future for dental education? British Dental Journal. 2002;193(2):111-2.

7. Elkind A, Blinkhorn A, Blinkhorn F, Duxbury J, Hull P, Brunton P. Developing dental education in primary care: the student perspective. British Dental Journal. 2005;198(4):233.

8. Smith M, Lennon MA, Brook AH, Ritucci L, Robinson PG. Student perspectives on their recent dental outreach placement experiences. European Journal of Dental Education. 2006;10(2):80-6.

9. Smith M, Lennon MA, Robinson PG. The Sheffield outreach teaching programme. British Dental Journal. 2010;209(10):513-20.

10. Blinkhorn FA. Evaluation of an undergraduate community - based course in Family Dentistry. European Journal of Dental Education. 2002;6(1):40-4.

11. Waterhouse P, Maguire A, Tabari D, Hind V, Lloyd J. The development of a primary dental care outreach course. European Journal of Dental Education. 2008;12(1):8-16.

12. Hind V, Waterhouse PJ, Maguire A, Tabari D, Lloyd J. Developing a primary dental care outreach (PDCO) course-part 1: practical issues and evaluation of clinical activity. European Journal of Dental Education. 2009;13(4):203-9.

13. Maguire A, Hind V, Waterhouse PJ, Tabari D, Steen IN, Lloyd J. Developing a primary dental care outreach (PDCO) course-part 2: perceptions of dental students. European Journal of Dental Education. 2009;13(4):210-7.

14. Hunter ML, Chaudhry U. Paediatric dentistry in outreach settings: an essential part of undergraduate curricula? European Journal of Dental Education. 2009;13(4):199-202.

15. Magee AP. View from the North End: a model for future dental schools? Dental Update. 2015;42(8):701-3.

16. Bridgett G. Expansion of Dental Training Places - summary proforma of NHS capital requirements. Internal report, the University of Liverpool in collaboration with other HEI and NHS partners. 2005:Unpublished.

17. Isringhausen KT, VanderWielen LM, Vanderbilt AA. Addressing Health Care Disparities and Access to Dental Care while Improving Education: Schools of Dentistry and Federally Qualified Health Centers. Journal of Health Care for the Poor and Underserved. 2014;25(2):670-4.

18. Rohra AK, Piskorowski WA, Inglehart MR. Community-based dental education and dentists' attitudes and behavior concerning patients from underserved populations. Journal of Dental Education. 2014;78(1):119-30.

19. Health Education England 2018 Dental Foundation Recruitment 2018/19, Presentation. Available online from http://www.copdend.org/postgraduate-training/dft-recruitment-2018/ accessed on 16/11/2018]

20. Ltd QIP. NVivo qualitative data analysis Software. Version 11. 2015. 
21. Braun V, Clarke V. Using thematic analysis in psychology. Qualitative Research in Psychology. 2006;3(2):77-101.

22. Radford DR, Hellyer P. Dental students perception's of their experience at a residential outreach centre. British Dental Journal. 2015;219:171.

23. Ray M, Milston A, Doherty P, Crean S. In their own words: investigating the preparedness of final year dental students in the UK for independent general dental practice. British Dental Journal. 2018;225(4):340-349

24. Radford DR, Holmes S, Dunne M and Woolford MJ. Outreach clinical dental education: the Portsmouth experience - a 4-year follow-up study. European Journal of Dental Education. 2016. 20:148-155

25. Kay EJ. Dental education-where it needs to be. Dentistry for the community. British Dental Journal. 2007;202(1):1-.

26. McHarg J, Kay EJ. Designing a dental curriculum for the twenty-first century. British Dental Journal. 2009;207(10):493-7.

27. Fyffe HE, Pitts NB. Origin, training, and subsequent practice location of Scotland's General and Community dentists. Community Dentistry and Oral Epidemiology. 1989;17(6):325-9.

28. Lennon MA, Sharples J. Factors influencing dentists' choice of practice location. British Dental Journal. 1979;146(12):379-81.

29. Pelton WJ, Pennell EH, Pennell MY. Location of dentists in relation to dental school attended. Public Health Reports. 1955;70(12):1237-41.

30. Malterud K, Siersma VD, Guassora AD. Sample size in qualitative interview studies: guided by information power. Qualitative Health Research 2016;26(143):1753-1760

31. Health Education England. Advancing Dental Care - final report. 2018. Available online from https://www.hee.nhs.uk/our-work/advancing-dental-care 